\title{
Evaluation of genetic diversity in Piper spp using RAPD and SRAP markers
}

\author{
Y. Jiang ${ }^{1}$ and J.-P. Liu ${ }^{2}$
}

${ }^{1}$ Key Laboratory of Protection and Development Utilization of Tropical Crop Germplasm Resources, Hainan University, Ministry of Education, Haikou, Hainan Province, China

${ }^{2}$ College of Agronomy, Hainan University, Danzhou, Hainan Province, China

Corresponding author: J.-P. Liu

E-mail: liu3305602@163.com

Genet. Mol. Res. 10 (4): 2934-2943 (2011)

Received January 21, 2011

Accepted June 11, 2011

Published November 29, 2011

DOI http://dx.doi.org/10.4238/2011.November.29.4

\begin{abstract}
Random amplified polymorphic DNA (RAPD) and sequence-related amplified polymorphism (SRAP) analysis were applied to 74 individual plants of Piper spp in Hainan Island. The results showed that the SRAP technique may be more informative and more efficient and effective for studying genetic diversity of Piper spp than the RAPD technique. The overall level of genetic diversity among Piper spp in Hainan was relatively high, with the mean Shannon diversity index being 0.2822 and 0.2909 , and the mean Nei's genetic diversity being 0.1880 and 0.1947 , calculated with RAPD and SRAP data, respectively. The ranges of the genetic similarity coefficient were 0.486-0.991 and 0.520-1.000 for 74 individual plants of Piper spp (the mean genetic distance was 0.505 and 0.480 ) and the within-species genetic distance ranged from 0.063 to 0.291 and from 0.096 to 0.234 , estimated with RAPD and SRAP data, respectively. These genetic indices indicated that these species are closely related genetically. The dendrogram generated with the RAPD markers was topologically different from the dendrogram based on SRAP markers, but the SRAP technique clearly distinguished all Piper spp from each other. Evaluation of genetic variation levels of six populations showed that
\end{abstract}


the effective number of alleles, Nei's gene diversity and the Shannon information index within Jianfengling and Diaoluoshan populations are higher than those elsewhere; consequently conservation of wild resources of Piper in these two regions should have priority.

Key words: Piper; Genetic diversity; Molecular marker; RAPD; SRAP

\section{INTRODUCTION}

The genus Piper is widely distributed in pan-tropical areas, with black pepper (Piper nigrum) being the most important commercial spice crop (known as "King of Spices"). China is one of the main producers of black pepper. Hainan Island accounts for over $80 \%$ of annual production and is one of the most important biodiversity-rich areas in China, with 11 Piper spp being recorded (Cheng, 1964; Zheng, 1999). Some wild relatives naturally distributed in Hainan have been used locally for spice, medicine and as vegetables before black pepper was introduced from abroad (Liu, 2010). Molecular characterization of these wild species is needed for the development, utilization and conservation of the wild pepper resources; this type of information will help us understand the level of genetic diversity and geographical distribution of genetic variation.

DNA markers offer many advantages over morphological characters for the determination of genetic diversity and the identification of species, such as not being influenced by the environment and detection directly at the DNA level. There have been few studies on genetic diversity of Indian black pepper using molecular markers (Pradeepkumar et al., 2003; Joy et al., 2007). However, the Piper spp that are distributed naturally in China have not been investigated to determine their genetic diversity and genetic relationships with each other.

The utility of RAPD technique or sequence-related amplified polymorphism (SRAP) as genetic markers for assessing genetic variation among plants has been clearly established (Williams et al., 1990; Welsh and McClelland, 1990; Morgante and Olivieri, 1993; Gupta et al., 1994; Thormann et al., 1994; Ferriol et al., 2003a,b). We analyzed the genetic diversity of the Piper spp in Hainan employing RAPD and SRAP markers. To our knowledge, this is the first report on the characterization of genetic variation present among species in Piper naturally distributed in Hainan Island, China.

\section{MATERIAL AND METHODS}

\section{Plant materials and DNA extraction}

Seventy-four accessions of the species $P$. hainanense, $P$. bonii, $P$. laetispicum, $P$. curtipedunculum, . austrosinense, $P$. kadsura, $P$. puberulum, $P$. boehmeriaefolium, $P$. sarmentosum, $P$. betle, and three black pepper (P. nigrum) varieties Kuching, Lampong Type (Lampung Broad Leaf) and Panniyur-1 collected from Jianfengling (A1-A23, thus designated as Pop1), Diaoluoshan (B1-B19, Pop2), Limushan (C1-C5, Pop3), Wuzhishan (D1-D22, Pop4), Xinglong tropical botanical garden (E1-E2, Pop5), and Danzhou (F1-F3, Pop6) were included in our study (Table 1). Genomic DNA from leaves of 10 plants per accession was extracted and purified, as described by Jang and Liu (2009), and diluted to $50 \mathrm{ng} / \mu \mathrm{L}$ for use. 
Table 1. Accession number (Acc. No.), species (and variety name) and sources of the Piper spp.

\begin{tabular}{|c|c|c|c|c|c|}
\hline Acc. No. & Species & Source & Acc. No. & Species & Source \\
\hline A1 & P. hainanense & Jianfengling & B15 & P. curtipedunculum & Diaoluoshan \\
\hline $\mathrm{A} 2$ & P. hainanense & Jianfengling & B16 & P. curtipedunculum & Diaoluoshan \\
\hline A 3 & P. bonii & Jianfengling & B17 & P. curtipedunculum & Diaoluoshan \\
\hline A4 & P. laetispicum & Jianfengling & B18 & P. curtipedunculum & Diaoluoshan \\
\hline A5 & P. laetispicum & Jianfengling & B19 & P. curtipedunculum & Diaoluoshan \\
\hline A6 & P. curtipedunculum & Jianfengling & $\mathrm{C} 1$ & P. austrosinense & Limushan \\
\hline A7 & P. hainanense & Jianfengling & $\mathrm{C} 2$ & P. curtipedunculum & Limushan \\
\hline A8 & P. curtipedunculum & Jianfengling & $\mathrm{C} 3$ & P. curtipedunculum & Limushan \\
\hline A9 & P. laetispicum & Jianfengling & $\mathrm{C} 4$ & P. austrosinense & Limushan \\
\hline A10 & P. hainanense & Jianfengling & $\mathrm{C} 5$ & P. curtipedunculum & Limushan \\
\hline A11 & P. laetispicum & Jianfengling & D1 & P. puberulum & Wuzhishan \\
\hline A12 & P. hainanense & Jianfengling & D2 & P. kadsura & Wuzhishan \\
\hline A13 & P. laetispicum & Jianfengling & D3 & P. puberulum & Wuzhishan \\
\hline A14 & P. laetispicum & Jianfengling & D4 & P. kadsura & Wuzhishan \\
\hline A 15 & P. bonii & Jianfengling & D5 & P. kadsura & Wuzhishan \\
\hline A16 & P. hainanense & Jianfengling & D6 & P. puberulum & Wuzhishan \\
\hline A17 & P. curtipedunculum & Jianfengling & D7 & P. kadsura & Wuzhishan \\
\hline A 18 & P. hainanense & Jianfengling & D8 & P. puberulum & Wuzhishan \\
\hline A19 & P. hainanense & Jianfengling & D9 & P. puberulum & Wuzhishan \\
\hline A 20 & P. curtipedunculum & Jianfengling & D10 & P. puberulum & Wuzhishan \\
\hline A 21 & P. hainanense & Jianfengling & D11 & P. puberulum & Wuzhishan \\
\hline A 22 & P. hainanense & Jianfengling & D12 & P. puberulum & Wuzhishan \\
\hline A 23 & P. hainanense & Jianfengling & D13 & P. puberulum & Wuzhishan \\
\hline B1 & P. curtipedunculum & Diaoluoshan & D14 & P. puberulum & Wuzhishan \\
\hline B2 & P. hainanense & Diaoluoshan & D15 & P. puberulum & Wuzhishan \\
\hline B3 & P. hainanense & Diaoluoshan & D16 & P. puberulum & Wuzhishan \\
\hline B4 & P. hainanense & Diaoluoshan & D17 & P. puberulum & Wuzhishan \\
\hline B5 & P. curtipedunculum & Diaoluoshan & D18 & P. puberulum & Wuzhishan \\
\hline B6 & P. curtipedunculum & Diaoluoshan & D19 & P. puberulum & Wuzhishan \\
\hline B7 & P. curtipedunculum & Diaoluoshan & D20 & P. puberulum & Wuzhishan \\
\hline B8 & P. laetispicum & Diaoluoshan & $\mathrm{D} 21$ & P. boehmeriaefolium & Wuzhishan \\
\hline B9 & P. curtipedunculum & Diaoluoshan & $\mathrm{D} 22$ & P. austrosinense & Wuzhishan \\
\hline B10 & P. hainanense & Diaoluoshan & E1 & P. nigrum var. Lampong Type & Xinglong Tropical Botanical Garden \\
\hline B11 & P. hainanense & Diaoluoshan & E2 & P. nigrum var. Panniyur-1 & Xinglong Tropical Botanical Garden \\
\hline B12 & P. curtipedunculum & Diaoluoshan & $\mathrm{F} 1$ & P. sarmentosum & Danzhou \\
\hline B13 & P. curtipedunculum & Diaoluoshan & $\mathrm{F} 2$ & P. betle & Danzhou \\
\hline B14 & P. curtipedunculum & Diaoluoshan & F3 & P. nigrum var. Kuching & Danzhou \\
\hline
\end{tabular}

\section{RAPD fingerprinting}

Nine selected 10-mer primers (Life Technologies, Shanghai) were used for PCR amplification (Table 2). The reaction mixture, with a $20-\mu \mathrm{L}$ total volume, contained $1.0 \mathrm{U}$ Taq DNA polymerase (TaKaRa Biotechnology Co., Ltd., Dalian, China), 6X PCR buffer, $0.4 \mathrm{mM}$ dNTP, $0.25 \mu \mathrm{M}$ primer, $1.5 \mathrm{mM} \mathrm{Mg}{ }^{2+}$, and $25 \mathrm{ng}$ template DNA. PCR was performed in a thermocycler (Biometra T1 Thermocycle, German) with the following program: 5 min at $94^{\circ} \mathrm{C}$ for initial denaturing, followed by 6 cycles of $30 \mathrm{~s}$ at $94^{\circ} \mathrm{C}, 30 \mathrm{~s}$ at $32^{\circ} \mathrm{C}$ and $45 \mathrm{~s}$ at $72^{\circ} \mathrm{C}$. The last cycle was followed by a 7 -min extension at $72^{\circ} \mathrm{C}$. Amplified products were analyzed on $2 \%(\mathrm{w} / \mathrm{v})$ gels and visualized on Vilber Gel Documentation System (Viber Lourmat).

\section{SRAP fingerprinting}

Nine selected pairs of primers (Life Technologies) from 121 different primer combinations were used for detecting polymorphism in open reading frames (ORFs) (Table 3). Each $20-\mu \mathrm{L}$ PCR mixture consisted of 1.0 U Taq DNA polymerase (TaKaRa Biotechnology), 
6X PCR buffer, $0.6 \mathrm{mM}$ dNTP, $0.35 \mu \mathrm{M}$ primer, $1.5 \mathrm{mM} \mathrm{Mg}^{2+}$, and 25-200 ng template DNA. Thermal cycling (Biometra T1 Thermocycle) started with 5 min at $94^{\circ} \mathrm{C}$ for initial denaturing, and 5 cycles of $30 \mathrm{~s}$ at $94^{\circ} \mathrm{C}, 30 \mathrm{~s}$ at $35^{\circ} \mathrm{C}$, and $45 \mathrm{~s}$ at $72^{\circ} \mathrm{C}$, followed by 40 cycles of $30 \mathrm{~s}$ at $94^{\circ} \mathrm{C}, 30 \mathrm{~s}$ at $4^{\circ} \mathrm{C}$ and $45 \mathrm{~s}$ at $72^{\circ} \mathrm{C}$. The last cycle was followed by a 7 -min extension at $72^{\circ} \mathrm{C}$. Amplified products were analyzed on $2 \%(\mathrm{w} / \mathrm{v})$ gels and visualized with the Vilber Gel Documentation System.

\section{Data analysis}

RAPD and SRAP analyzes were repeated twice and only clear bands produced both times were recorded for all samples. For each primer (RAPD) or primer combination (SRAP), the presence or absence of bands in each individual plants was visually scored. Data were set in a binary matrix, genetic similarities were calculated with NTSYS-pc (Numerical Taxonomy and Multivariate Analysis System) version 2.0 (Rohlf, 1998). Clustering analysis was conducted using the unweighted pair group method with arithematic mean (UPGMA). The mean Shannon diversity index $(I)$, the mean Nei's $(1978)$ genetic diversity $(H)$, the mean number of alleles per locus $\left(N_{\mathrm{A}}\right)$, and the effective number of alleles per locus $\left(N_{\mathrm{E}}\right)$ were estimated by POPGENE version 1.32 (Yeh et al., 1997).

\section{RESULTS}

The 9 selected RAPD primers generated 111 amplified products, with a mean of 11.1 bands per primer, ranging from 9 (ba45, ba106 and s02) to 14 (ba01 and s20) (Figure 1, Table 2). Of the bands, 110 were polymorphic $(99.1 \%$ ) with the size of the bands ranging from 250 to 1000 bp. The mean $I$ was 0.2822 , the mean $H$ was 0.1880 , the mean $N_{\mathrm{A}}$ was 1.6436 , and $N_{\mathrm{E}}$ was 1.3186 .

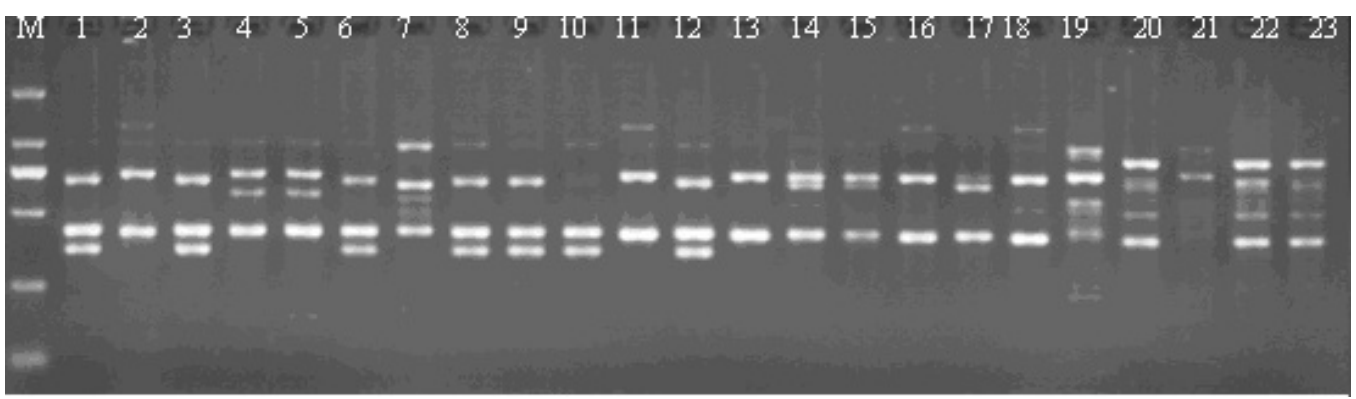

Figure 1. Gel electrophoresis of amplification products obtained with primer ba45. Lane $M=$ molecular marker (DL2000); lanes 1-23 = samples.

Analysis of the 74 individual plants of Piper spp with nine SRAP primer combinations identified 127 reproducible fragments, with an average of 14.1 bands per primer (Figure 2 , Table 3). The highest number of fragments was 16 for the primers me9em1 and me8em10, and the lowest number of fragments was 11 for the primer me7em10. Amplified DNA fragments varied in size from 100 to $2000 \mathrm{bp}$. All 127 bands were polymorphic. The mean $I$ was 0.2909 , the mean $H$ was 0.1947 , the mean $N_{\mathrm{A}}$ was 1.5499 , and $N_{\mathrm{E}}$ was 1.3331 . 
Table 2. RAPD primer sequences and the polymorphism of their products.

\begin{tabular}{llccc}
\hline Primer order & Sequence & Total bands & Polymorphic bands & PPB $(\%)$ \\
\hline ba01 & CCGTCGGTAG & 14 & 14 & 13 \\
ba38 & AGGTGACCGT & 13 & 8 & 100 \\
ba45 & TCAGAGCGCC & 9 & 9 & 88.9 \\
ba106 & ACACGTGGTC & 9 & 9 & 100 \\
s02 & TGATCCCTGG & 9 & 12 & 100 \\
s08 & GTCCACACGG & 12 & 12 & 100 \\
s14 & TCCGCTCTGG & 12 & 12 & 100 \\
s20 & GGACCCTTAC & 14 & 10 & 100 \\
s1172 & CACTCTCCTC & 10 & 110 & 99.1 \\
Total & & 111 & & \\
\hline
\end{tabular}

$\mathrm{PPB}=$ percentage of polymorphic bands.

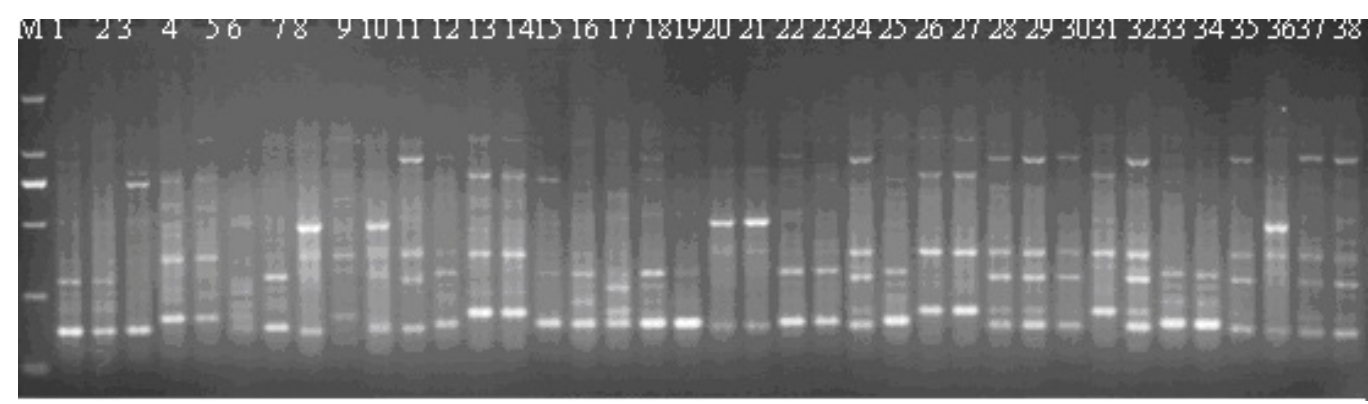

Figure 2. Gel electrophoresis of amplification products obtained with the primer combination me3em6. Lane $M=$ molecular marker (DL2000); lanes 1-38= samples.

Table 3. SRAP primer sequences and the polymorphism of their products.

\begin{tabular}{|c|c|c|c|c|}
\hline Primer order & Sequence & Total bands & Polymorphic bands & PPB (\%) \\
\hline me3em 6 & $\begin{array}{l}\text { me3 TGAGTCCAAACCGGACC } \\
\text { em6 GACTGCGTACGAATTGAC }\end{array}$ & 15 & 15 & 100 \\
\hline me 3 em 9 & $\begin{array}{l}\text { me3 TGAGTCCAAACCGGACC } \\
\text { em9 GACTGCGTACGAATTGCA }\end{array}$ & 13 & 13 & 100 \\
\hline me7em 10 & $\begin{array}{l}\text { me7 TGAGTCCAAACCGGAAG } \\
\text { em10 GACTGCGTACGAATTCAA }\end{array}$ & 11 & 11 & 100 \\
\hline me8em 1 & $\begin{array}{l}\text { me8 TGAGTCCAAACCGGTAA } \\
\text { em1 GACTGCGTACGAATTTGC }\end{array}$ & 14 & 14 & 100 \\
\hline me8em 10 & $\begin{array}{l}\text { me8 TGAGTCCAAACCGGTAA } \\
\text { em10 GACTGCGTACGAATTCAA }\end{array}$ & 16 & 16 & 100 \\
\hline me9em 1 & $\begin{array}{l}\text { me9 TGAGTCCAAACCGGTCC } \\
\text { em1 GACTGCGTACGAATTTGC }\end{array}$ & 16 & 16 & 100 \\
\hline me2em9 & $\begin{array}{l}\text { me2 TGAGTCCAAACCGGAGC } \\
\text { em9 GACTGCGTACGAATTGCA }\end{array}$ & 14 & 14 & 100 \\
\hline me 5 em 4 & $\begin{array}{l}\text { me5 5TGAGTCCAAACCGGTGT } \\
\text { em4 GACTGCGTACGAATTCCA }\end{array}$ & 14 & 14 & 100 \\
\hline me4em 8 & $\begin{array}{l}\text { me4 TGAGTCCAAACCGGTAG } \\
\text { em8 GACTGCGTACGAATTAAC }\end{array}$ & 14 & 14 & 100 \\
\hline Total & & 127 & 127 & 100 \\
\hline
\end{tabular}

$\mathrm{PPB}=$ percentage of polymorphic bands.

The calculated genetic similarity coefficient for RAPD and SRAP markers ranged from 0.486 to 0.991 , with a mean of 0.7385 and from 0.5197 to 1.000 , with an average of 0.7599 , respectively. These results indicated that these species are closely related. In more 
detail, genetic similarity values based on RAPD and SRAP markers ranged from 0.806-0.939 and $0.784-0.978$ in $P$. hainanense (with a genetic distance of 0.133 and 0.194 ), 0.664-0.955 and $0.708-0.942$ in P. curtipedunculum (0.291 and 0.234), 0.664-0.930 and 0.769-1.000 in P. laetispicum (0.266 and 0.231), 0.0.806-0.991 and 0.821-0.959 in P. puberulum (0.185 and $0.138), 0.874-0.971$ and $0.822-0.951$ in $P$. kadsura (0.097 and 0.129), 0.892-0.955 and 0.8220.918 in P. nigrum (0.063 and 0.096), and 0.841-0.912 and 0.708-0.886 in P. austrosinense (0.071 and 0.178), respectively.

The dendrogram generated with the RAPD markers was topologically different from the dendrogram based on SRAP markers (Figures 3 and 4). The dendrogram based on the RAPD data grouped the species into five clusters at a genetic similarity of 0.66: P. hainanense and $P$. bonii in one cluster, $P$. austrosinense, $P$. puberulum and $P$. boehmeriaefolium in one, $P$. nigrum, $P$. sarmentosum and $P$. betle in one, P. laetispicum and P. curtipedunculum in one, and $P$. kadsura in one. In the dendrogram generated with SRAP markers, at genetic similarity of $0.68, P$. hainanense, $P$. bonii and $P$. curtipedunculum shared a group, $P$. puberulum, $P$. boehmeriaefolium, $P$. sarmentosum, $P$. betle and $P$. nigrum were placed in a group, and $P$. laetispicum, $P$. kadsura and $P$. austrosinense grouped separately in three different groups. Both dendrograms separated $P$. nigrum, $P$. sarmentosum and $P$. betle from the rest, but the dendrogram based on the RAPD data did not differentiate $P$. curtipedunculum from $P$. laetispicum. In contrast, the dendrogram based on SRAP markers unambiguously distinguished all Piper spp from each other. The high level of genetic variation detected by SRAP was consistent with the observed morphological variability, and the results obtained

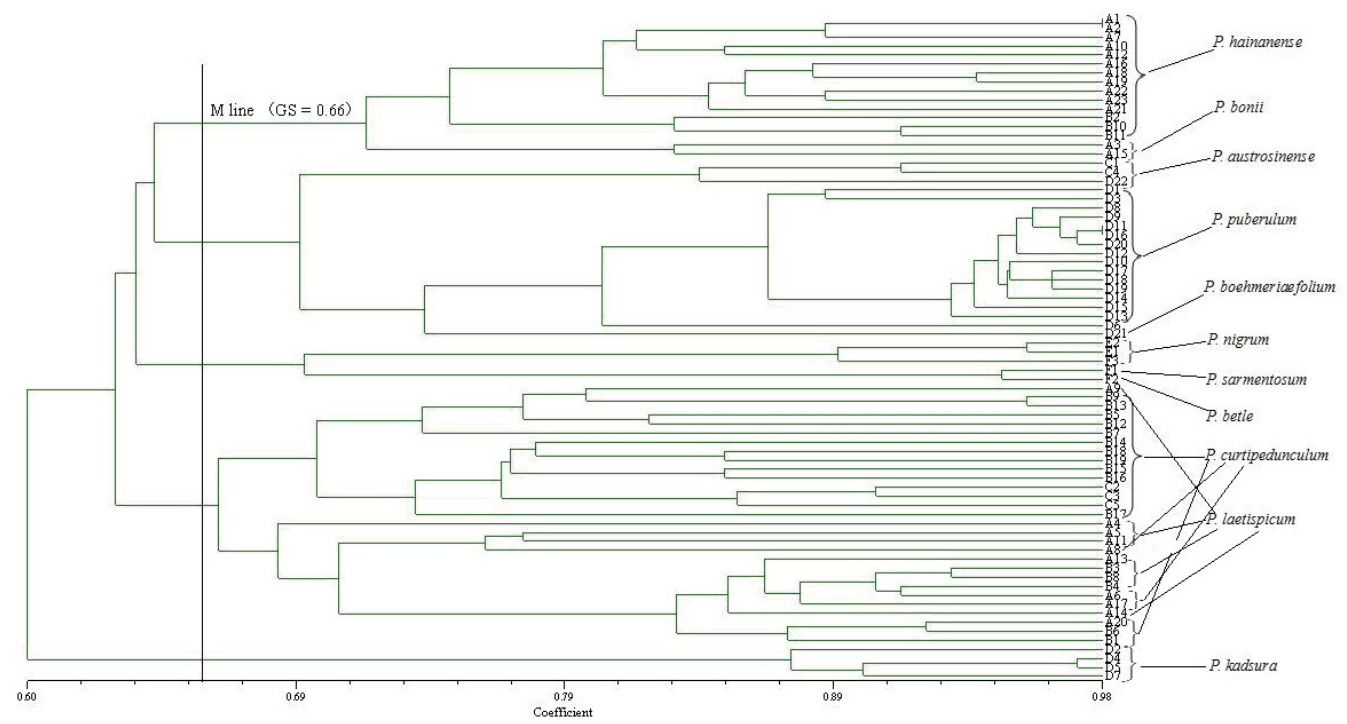

Figure 3. The UPGMA dendrogram illustrating the genetic relationships between the 74 accessions based on RAPD analysis. Piper hainanense (A1, A2, A7, A10, A12, A16, A18, A19, A21, A22, A23, B2, B3, B4, B10, B11), P. bonii (A3, A15), P. laetispicum (A4, A5, A9, A11, A13, A14, B8), P. curtipedunculum (A6, A8, A17, A20, B1, B5, B6, B7, B9, B12, B13, B14, B15, B16, B17, B18, B19, C2, C3, C5), P. austrosinense (C1, C4, D22), $P$. puberulum (D1, D3, D6, D8, D9, D10, D11, D12, D13, D14, D15, D16, D17, D18, D19, D20), P. kadsura (D2, D4, D5, D7), P. boehmeriaefolium (D21), P. nigrum (E1, E2, F3), P. sarmentosum (F1), and P. betle (F2). 


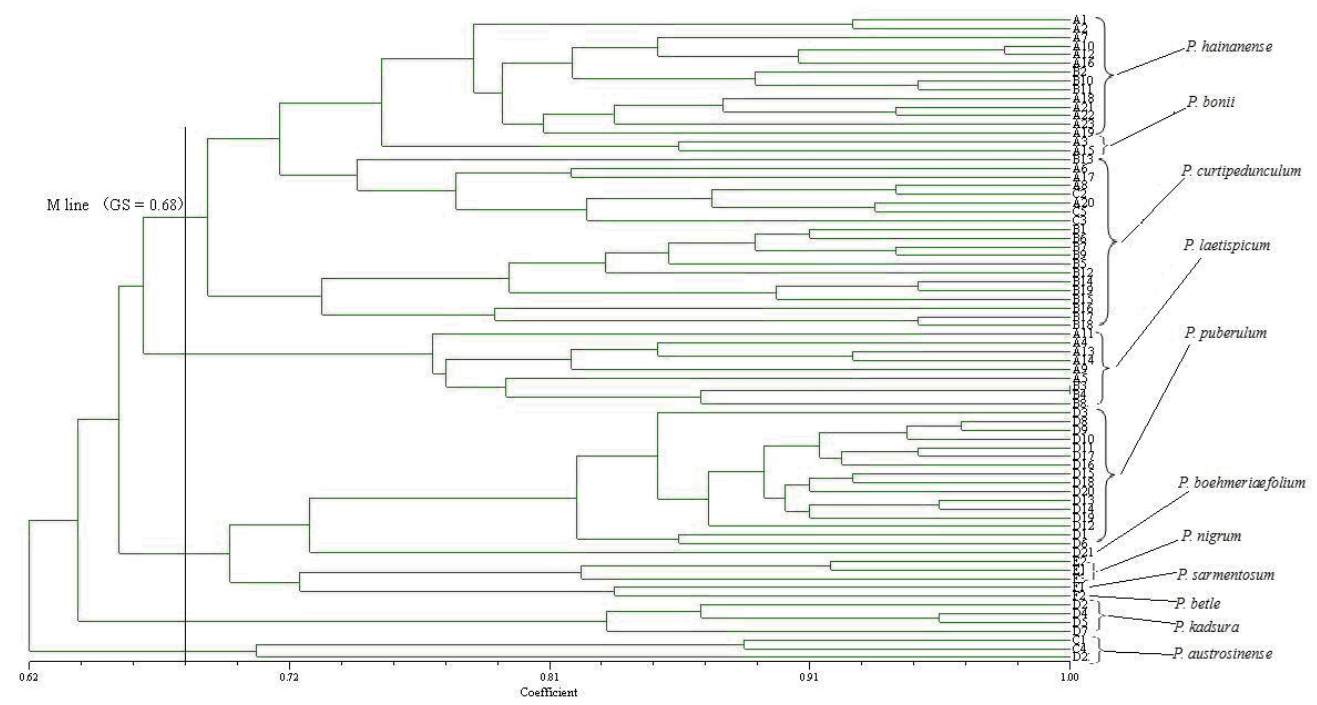

Figure 4. The UPGMA dendrogram illustrating the genetic relationships between the 74 accessions based on SRAP analysis. Piper hainanense (A1, A2, A7, A10, A12, A16, A18, A19, A21, A22, A23, B2, B3, B4, B10, B11), P. bonii (A3, A15), P. laetispicum (A4, A5, A9, A11, A13, A14, B8), P. curtipedunculum (A6, A8, A17, A20, B1, B5, B6, B7, B9, B12, B13, B14, B15, B16, B17, B18, B19, C2, C3, C5), P. austrosinense (C1, C4, D22), P. puberulum (D1, D3, D6, D8, D9, D10, D11, D12, D13, D14, D15, D16, D17, D18, D19, D20), P. kadsura (D2, D4, D5, D7), P. boehmeriaefolium (D21), P. nigrum (E1, E2, F3), P. sarmentosum (F1), and P. betle (F2).

with SRAP analysis were in accordance with the morphological classification. In addition, the dendrograms clearly indicated that there was no correlation between the marker-based grouping pattern and geographical origin.

Seventy-four accessions were collected from Jianfengling (A1-A23, designated as Pop1), Diaoluoshan (B1-B19, Pop2), Limushan (C1-C5, Pop3), Wuzhishan (D1-D22, Pop4), Xinglong Tropical Botanical Garden (E1-E2, Pop5), and Danzhou (F1-F3, Pop6). To estimate genetic variation levels of each population, all the statistical analyses were performed using the POPGENE program (version 1.32) (Tables 4 and 5). Based on RAPD and SRAP data, the observed $N_{\mathrm{A}}$ within the populations ranged from 1.0450 to 1.8739 and from 1.0866 to 1.7795 , with the mean observed $N_{\mathrm{A}}$ being 1.9910 and 2.0000 , respectively. The $N_{\mathrm{E}}$ within the populations ranged from 1.0450 to 1.4983 and from 1.0866 to 1.4425 , with the mean $N_{\mathrm{E}}$ being 1.5718 and 1.5202 , respectively. The $H$ within the populations ranged from 0.0225 to 0.2947 and from 0.0433 to 0.2632 , with the mean $H$ being 0.3327 and 0.3123 , respectively. The $I$ within the populations ranged from 0.0312 to 0.4445 and from 0.0600 to 0.3977 , with the mean $I$ being 0.4994 and 0.4752 , respectively. Estimation with both RAPD and SRAP markers showed that the lowest value of within-population variation was in Pop5. Overall, the populations included in this study showed a relatively high level of genetic diversity. The fact that Pop1 and Pop2 clustered together in the dendrograms demonstrated that they are closely related, while the genetic distance between Pop1 and Pop6 was the largest (Figures 5 and 6). 
Table 4. Descriptive statistics based on RAPD data for 6 Piper populations in Hainan, China.

\begin{tabular}{lccccc}
\hline Populations & Sample size & $N_{\mathrm{A}}$ & $N_{\mathrm{E}}$ & $H$ & \multicolumn{1}{c}{$I$} \\
\hline Pop1 & 23 & 1.8739 & 1.4983 & 0.2947 & 0.4445 \\
Pop2 & 19 & 1.7748 & 1.4391 & 0.1903 & 0.4008 \\
Pop3 & 5 & 1.4414 & 1.3463 & 0.1994 & 0.2738 \\
Pop4 & 22 & 1.7748 & 1.3016 & 0.0225 & 0.1562 \\
Pop5 & 2 & 1.0450 & 1.0450 & 0.3327 & 0.2236 \\
Pop6 & 3 & 1.3514 & 1.2811 & 0.4994 \\
Mean & 74 & 1.9910 & 1.5718 & 0.1514 & 0.1883 \\
SD & & 0.0949 & 0.3301 & & \\
\hline
\end{tabular}

$N_{\mathrm{A}}=$ observed number of alleles; $N_{\mathrm{E}}=$ effective number of alleles; $H=$ Nei's gene diversity; $I=$ Shannon information index; Pop1 = population from Jianfengling; Pop2 = population from Diaoluoshan; Pop3 = population from Limushan; Pop4 = population from Wuzhishan; Pop5 = population from Xinglong Tropical Botanical Garden; Pop6 = population from Danzhou.

Table 5. Descriptive statistics based on SRAP data for 6 Piper populations in Hainan, China.

\begin{tabular}{lccccc}
\hline Populations & Sample size & $N_{\mathrm{A}}$ & $N_{\mathrm{E}}$ & $H$ & \multicolumn{1}{c}{${ }$} \\
\hline Pop1 & 23 & 1.7795 & 1.4358 & 0.2593 & 0.2632 \\
Pop2 & 19 & 1.7795 & 1.4425 & 0.2280 & 0.3977 \\
Pop3 & 5 & 1.5512 & 1.4055 & 0.2204 & 0.3315 \\
Pop4 & 22 & 1.7559 & 1.3512 & 0.0433 & 0.3434 \\
Pop5 & 2 & 1.0866 & 1.0866 & 0.1540 & 0.0600 \\
Pop6 & 3 & 1.3465 & 1.2772 & 0.3123 & 0.2205 \\
Mean & 74 & 2.0000 & 1.5202 & 0.1491 & 0.4752 \\
SD & & 0.0000 & 0.3121 & 0.1886 \\
\hline
\end{tabular}

For abbreviations, see legend to Table 4.

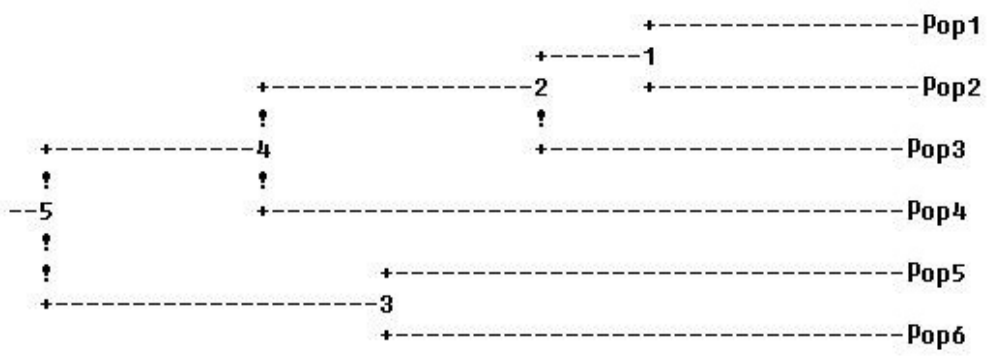

Figure 5. Dendrogram illustrating the genetic distance between six populations of Piper spp in Hainan, China, based on RAPD analysis.

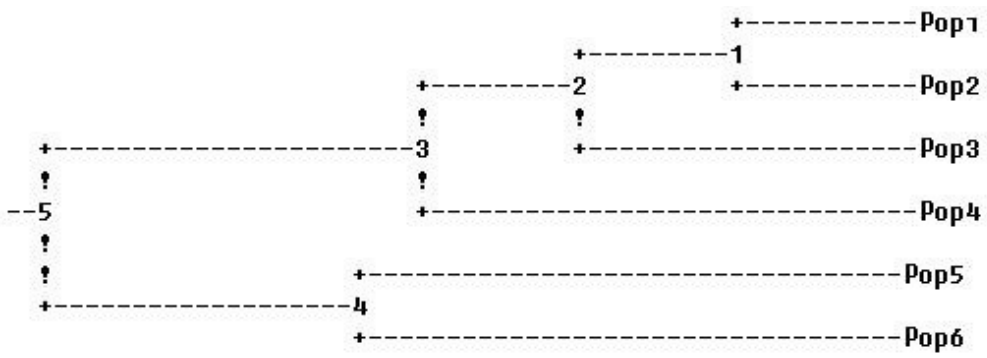

Figure 6. Dendrogram illustrating the genetic distance between six populations of Piper spp in Hainan, based on SRAP analysis. 


\section{DISCUSSION}

RAPD is one of the most widely used techniques for analysis of plant genetic diversity. Pradeepkumar et al. (2003) assessed genetic variation in 22 Indian cultivars of black pepper, including P. longum and P. colubrinum, using RAPD markers. In our study, the PPB (percentage of polymorphic bands) and the mean number of bands per primer detected with SRAP (100 and 14.1\%) were higher than those detected with RAPD (99.1 and 11.1\%). Moreover, the dendrogram based on the RAPD data did not discriminate P. curtipedunculum from $P$. laetispicum, but the dendrogram based on SRAP markers clearly distinguished all Piper spp from each other. The results show that the SRAP technique can be more informative and more efficient and effective for studying genetic diversity than the RAPD technique. The ability to evaluate genetic variation among species at the molecular level is directly related to the number of polymorphisms detected and their reproducibility (Nguyen et al., 2004). The RAPD technique involves the amplification of random segments of genomic DNA using random primers and a low annealing temperature, which allows non-specific binding to the DNA. SRAP markers preferentially amplify ORFs, which may include coding regions of the genome involved in morphological and agronomic traits, and likely reflect differences in coding sequences, which are thought to be relatively conserved among species (Ferriol et al., 2003b).

The high mean $I$ values $(0.2822$ and 0.2909$)$, the mean $H(0.1880$ and 0.1947$)$, the mean $N_{\mathrm{A}}$ (1.6436 and 1.5499), and the $N_{\mathrm{E}}$ (1.3186 and 1.3331) estimated with RAPD and SRAP data, respectively, compared with those for plants in general, indicated that the level of genetic diversity among individual plants of Piper spp in Hainan is high and conservation of wild pepper germplasm has been effective (Zheng, 1999; Nybom, 2004). The genetic similarity among three cultivars (Lampong Type, Panniyur-1, Kuching) of P. nigrum introduced from abroad was higher than that of the Piper spp naturally distributed in Hainan, demonstrating that breeding practices tend to narrow the genetic base.

Evaluation of genetic variation levels of six populations (Pop1 from Jianfengling, Pop2 from Diaoluoshan, Pop3 from Limushan, Pop4 from Wuzhishan, Pop5 from Xinglong Tropical Botanical Garden, and Pop6 from Danzhou) showed that the effective number of alleles, Nei's gene diversity and Shannon information index within Pop1 and Pop2 were higher than those elsewhere; consequently, conservation of wild resources of Piper in these two regions should take priority. The high genetic variability observed in these regions confirms their distinction as centers of diversity of Piper (Zheng, 1999).

\section{ACKNOWLEDGMENTS}

The authors thank Dr. Wu of the Xinglong Tropical Botanical Garden for providing plant materials used in this study. Research supported by the National Natural Science Foundation of China (\#31060204).

\section{REFERENCES}

Cheng HY (1964). Flora of Hainan (Vol. I). Science Press, Beijing.

Ferriol M, Picó BM and Nuez F (2003a). Genetic diversity of some accessions of Cucurbita maxima form Spain using RAPD and SBAP markers. Genet. Res. Crop Evol. 50: 227-238.

Ferriol M, Pico B and Nuez F (2003b). Genetic diversity of a germplasm collection of Cucurbita pepo using SRAP and 
AFLP markers. Theor. Appl. Genet. 107: 271-282.

Gupta M, Chyi YS, Romero-Severson J and Owen JL (1994). Amplification of DNA markers from evolutionarily diverse genomes using single primers of simple-sequence repeats. Theor. Appl. Genet. 89: 998-1006.

Jang Y and Liu JP (2009). A comparison of extraction methods of genomic DNA from black pepper. Biotechnology 19: 41-44.

Joy N, Abraham Z and Soniya EV (2007). A preliminary assessment of genetic relationships among agronomically important cultivars of black pepper. BMC Genetics 8: 42.

Liu JP (2010). Development and utilization of wild pepper resources in Hainan. China Trop. Agr. 2: 35-36.

Morgante M and Olivieri AM (1993). PCR-amplified microsatellites as markers in plant genetics. Plant J. 3: 175-182.

Nei M (1978). Estimation of average heterozygosity and genetic distance from a small number of individuals. Genetics 89: 583-590.

Nguyen TT, Taylor PWJ, Redden RJ and Ford R (2004). Genetic diversity estimates in Cicer using AFLP analysis. Plant Breed. 123: 173-179.

Nybom H (2004). Comparison of different nuclear DNA markers for estimating intraspecific genetic diversity in plants. Mol. Ecol. 13: 1143-1155.

Pradeepkumar T, Karihaloo JL, Archak S and Baldev A (2003). Analysis of genetic diversity in Piper nigrum L. using RAPD markers. Genet. Res. Crop Evol. 50: 469-475.

Rohlf FJ (1998). NTSYS-pc: Numerical Taxonomy and Multivariate Analysis System, Version 2.0. Applied Biostatistics Inc., New York.

Thormann CE, Ferreira ME, Camargo LEA, Tivang JG, et al. (1994). Comparison of RELP and RAPD markers to estimating genetic relationships within and among cruciferous species. Theor. Appl. Genet. 88: 973-980.

Welsh J and McClelland M (1990). Fingerprinting genomes using PCR with arbitrary primers. Nucleic Acids Res 18: 7213-7218.

Williams JG, Kubelik AR, Livak KJ, Rafalski JA, et al. (1990). DNA polymorphisms amplified by arbitrary primers are useful as genetic markers. Nucleic Acids Res. 18: 6531-6535.

Yeh FC, Yang RC, Boyle TBJ, Ye ZH, et al. (1997). POPGENE, the User-Friendly Shareware for Population Genetic Analysis. Molecular Biology and Biotechnology Centre, University of Alberta, Canada. Available at [http://www. ualberta.ca/ fyeh/]. Accessed April 12, 2010.

Zheng WQ (1999). Germplasm resources of wild pepper and their use. Guangxi Sci. Technol. Trop. Crops 73: 12-13, 35. 